\title{
Reiteration Relations in EFL Student Writing: The Case of Moroccan University Students
}

\author{
Nadia Hellalet ${ }^{1}$ \\ ${ }^{1}$ College of Education Sciences, Mohammed V University, Souissi, Rabat, Morocco \\ Correspondence: Nadia Hellalet, College of Education Sciences, Mohammed V University, Souissi, Rabat, \\ Morocco. E-mail: hellaletnad@gmail.com
}

Received: July 29, 2013 Accepted: August 28, 2013 Online Published: October 10, 2013

doi:10.5539/elt.v6n11p160 URL: http://dx.doi.org/10.5539/elt.v6n11p160

\begin{abstract}
This study looks into the use of reiteration relations in EFL student writing. The aim is to determine the extent to which Moroccan college students rely on lexical cohesion to produce native-sounding texts. Twenty essays written by college students from two different levels were analyzed quantitatively using Halliday and Hasan's (1976) and Hoey's taxonomies (1991). The results of the independent sample T-test confirm previous studies, revealing that repetition is the most dominant cohesive relation used by students from both levels. However, the use of synonyms is not frequent in spite of the learners' language proficiency development. Students from both levels are also found to overuse conjunctions to connect their sentences as a result of their weak vocabulary and theirlack of awareness of the role of lexis in the creation of continuity and connectedness in their writings.
\end{abstract}

Keywords: cohesion, coherence, lexical cohesion, reiteration, writing

\section{Introduction}

Many researchers recognize the importance of lexis in the creation of continuity in text (Hasan, 1984; Hoey, 1991; Widowson, 1992). In this respect, lexical cohesion is considered a key factor in creating and interpreting discourse (Morris, 2004). However, there is a consensus that its exploration is in fact a challenge. As Sinclair (1998) points out, "the tools for lexical analysis remain unrefined, while grammar has gone through many stages of sophistication" (p. 3). This observation implies that researchers have given more attention to grammatical cohesion since its analysis is simpler than that of lexical cohesion, whose complexity comes from the flexibility and richness of lexis. This tendency in cohesion research has influenced the teaching of cohesion in writing. Many Moroccan EFL teachers believe that teaching cohesion means teaching conjunctions. As a consequence of this approach, the Moroccan EFL students' writings are characterized by an overuse of connectors (Hilali, 2000). The study at hand looks into the use of reiteration relations in EFL student writing. The objective is to find out how EFL students develop lexical cohesion in their writing.

\section{Background of the Study}

\subsection{Cohesion}

Cohesion may be defined as the way in which a sentence is connected to its predecessors in a passage by means of some lexical items and grammatical features; it refers to the elements on the surface level of text that connect its parts and help it form a unified whole. For Halliday and Hasan (1976) it is achieved "when the interpretation of some element in discourse is dependent on that of another. The one presupposes the other" (p. 4). Cohesion also covers units beyond the sentence level, which are the basis for discourse studies. For Michael Halliday and Ruqaiya Hasanthe semantic and syntactic links between pairs of elements in a text are the major contributors to the text's unity.

Cohesion for Markels (1983) is both a semantic and syntactic phenomenon. It is achieved when "a dominant term, explicit or implicit, occupies concurrently the most important semantic position in the paragraph and also the most important syntactic position in each sentence in the paragraph" (p. 453). Dominant is a key word here. For a term to be described as dominant it should consistently appear in the subject position. If it is repeated in each sentence but not in the subject position, it cannot be defined as a dominant term, and the cohesion of the paragraph is affected. In this sense, cohesive ties and chains should be considered with reference to their syntactic position because syntax is also important as it helps readers remember the content of the text and 
identify the topic of a passage by way of the dominant term.

\subsection{Coherence}

Coherence may be defined as a quality in text that enables the reader to make sense of it thanks to its organization according to some model of development. It is a complex concept, which has been subject to controversy among discourse analysts. Accordingly, two approaches to the term are distinguished, namely text-based and reader-based coherence.

Coherence, according to the text-based approach, refers to the semantic unity of text that is achieved by means of cohesive ties (Halliday and Hasan, 1976). That is, coherence is defined in terms of the linguistic features in the text that distinguish a text from a cluster of sentences. These linguistic features are the cohesive ties. Halliday and Hasan use the term "texture" to refer to coherence.

This approach has been criticized by many researchers who think that coherence is achieved through the relationships among sentences containing ideas that contribute to a text's rhetorical unity. Thus, analyzing the underlying propositional units in a text is more revealing than looking for the cohesive ties. In this respect, for a text to be coherent it should contain the following features: cohesion, organization (the orderly, systematic presentation of information), and register, which refers to situational consistency (Moe, 1979, p. 18). In this respect, writers should present information in a well-organized way and use the appropriate cohesive ties to create and facilitate comprehension.

As for the reader-based approach, coherence is achieved through the successful interaction between the reader and the text (Rumelhart, 1977; Widdowson 1978; Carrel 1982, 1984). It results from the reader's text knowledge and world knowledge (De Beaugrande and Dressler, 1981; Morgan and Sellner, 1980; Webber, 1980). That is, the reader is able to reconstruct the writer's meaning on the basis of the information and strategies the reader brings to the comprehension process and the text's cues.

\subsection{Lexical Cohesion}

Lexical cohesion is the unity achieved through the selection of vocabulary. It concerns the way in which lexical items are related to each other to create continuity. This category of cohesion is considered subjective because it relies in its analysis on the reader's perception of the lexical relations which are difficult to classify (Morris, 2004). It is among "the most vulnerable areas of cohesion theory" (Carrell, 1984). However, despite its importance in discourse analysis, it has been difficult to create a comprehensive and replicable model of analysisbased on it.

\subsubsection{Reiteration}

Halliday and Hasan (1976) define reiteration as "a form of lexical cohesion which involves the repetition of a lexical item, at one end of the scale; the use of a general word to refer back to a lexical item, at the other end of the scale; and a number of things in between - the use of a synonym, near-synonym, or superordinate" (p. 278). Reiteration involves the repetition of a lexical item as a repetition of the same word or as a synonymy, specification, co-specification, or contrast. Reiteration is seen as simpler and easier to identify in text than collocation since it is more systematic. Many studies, actually, used just the reiteration relations and excluded the collocation relations from the analysis of lexical cohesion. These studies cannot be considered incomplete according to Tanskenan (2007) since most of them contributed to our understanding of lexical cohesion.

\subsubsection{Collocation}

Halliday and Hasan (1976) define collocation as the sense created by the close co-occurrence of relatively low frequency words that tend to appear in similar contexts. It is the most problematic category of lexical cohesion. Many linguists refuse to deal with it because of its non-systematic nature. However, its contribution to coherence cannot be ignored. The effect of lexical cohesion, especially collocational cohesion on a text is subtle and difficult to estimate. With grammatical cohesion the effect is relatively clear (p. 288).

Halliday and Hasanconsider collocation as the most problematic part of lexical cohesion. It is achieved through the association of lexical items that regularly co-occur. Within this category, Halliday and Hasaninclude opposites, synonyms, near synonyms, pairs of words from the same ordered series (Monday, Tuesday...), as well as pairs drawn from unordered lexical sets (dollar/cent, north/south, hyponyms). In other words, it includes lexical items that tend to appear together in similar contexts. Nonetheless, words and phrases that tend to appear related in one text may not be related in another, which makes our perception of collocational relationships dependent on our background knowledge and our reading experiences. As Witt and Faigley (1981) put it, "Lexical collocations within a text are understood not only through the cues the writer provides, but also through 
the reader's knowledge of general discourse characteristics and the world to which the discourse refers (p. 200).

\subsection{The Effect of Grade Level on Learners' Use of Cohesion}

Halliday and Hasan's (1976) taxonomy was used by researchers to determine the developmental aspects of writing quality. Their findings reveal that lexical cohesion is the most dominant category of cohesion in learners' writings, and that lexical repetition represents the highest percentage. Yet, some categories of lexical cohesion are more frequently used than others depending on the learners' language proficiency.

Connor (1983) analyzed cohesion features in ESL students' compositions. Her findings reveal that the density of cohesive ties does not distinguish poor writing from good writing. She found out that ESL writers rely on lexical repetition as well as frequent use of synonyms and collocation. Native speakers rely on synonyms and collocation; the use of repetition is infrequent in native speakers' writings. She suggests that the use of lexical cohesion may be developmental. That is, ESL learners "may gradually develop to the native-speaker model as their English language proficiency increases" (p. 9). This development for Carrell (1983) is related to the students' vocabulary development.

Crowhurst (1987) investigated the kinds of cohesive ties used at three grade levels. He discovered that the most frequent kinds of cohesion used by students are repetition, pronouns, demonstratives, and the definite article. The use of synonyms and collocation increases significantly with grade level. The use of causal and temporal conjunctives, exophora, and repetition decreases with grade level. The sixth graders' use of repetition is attributed to their immature lexical choices. But the twelfth graders' use of repetition reflects their tendency to summarize and elaborate their arguments. The use of synonyms and collocation by the older students mirrors vocabulary development and an ability to elaborate arguments. These results are consistent with those of McCulley (1985), Stotsky (1983), and Witte and Faigley (1981).

Ferris (1994) analyzed a corpus of 160 ESL student compositions to determine the lexical and syntactic features used at different levels of second language proficiency. She found out that advanced students use a range of syntactic and lexical tools when writing, as well as a variety of cohesive devices and an assortment of lexical and referential cohesive devices such as synonymy, antonymy, definite articles, reference, and deictic reference. Less advanced students use more lexical repetition in their essays to promote textual cohesion.

Cherry and Cooper (1980) used the variable of average distance of ties to study average and superior writers' essays at grades four, eight, twelve, and at the college level. They conclude that writers tend to rely more on lexis and less on reference and conjunctions as they mature.

Witte and Faigley (1981) share Cherry and Cooper's findings. They used the frequency count of a simplified list of cohesive ties to analyze five good and five poor freshman essays to find out that two-thirds of the cohesive ties used by students were lexical. Other findings of the study reveal that the higher rated essays contain more cohesive ties, more reference and conjunctive ties, and more lexical collocation than the lower rated essays. The lower rated papers contain more lexical repetition than the higher rated ones. This finding may be interpreted as a result of some students' inadequate vocabularies and their poor ability to elaborate and expand ideas. Witte and Faigley consider lexical cohesion an indicator of writing quality. Hence, it is lexical collocation that distinguishes good writing from poor writing. They suggest that students should develop adequate working vocabularies to extend, explore, and elaborate the concepts they want to introduce. A limitation of Witte and Faigley'sstudy was the small number of subjects used in gathering data.

Hasewell (1988) questioned Cherry and Cooper's, Witte and Faigley's, and Neuner's findings (that good writers use cohesive ties twice as densely as poor writers), noting that the findings could be attributed to the fact that good writers write longer essays. Hasewell suggests using texts of equal length or whole texts of more or less equal length to control this variable.

Halliday and Hasan's (1976) taxonomy provesuseful in measuring sophisticated aspects of language development. It is more effective than error analysis and syntactic analysis. Witte and Faigley (1981) reported Maimon and Nodine's sentence combining experiment. The findings of the study suggest that certain kinds of errors accompany certain stages of learning to write as students are learning other skills and processes. Obviously, the developmental differences in the use of various cohesive devices can be anticipated since the developmental differences in both syntax and vocabulary are well established by research findings (Crowhurst, 1987).

\section{The Study}

This study looks into the reiteration relations used by Moroccan learners of English. The aim is to investigate the lexical ties used by the learners to write cohesive texts. Results are based on a quantitative analysis of twenty 
argumentative texts used to determine the extent to which the EFL learners make use of lexical cohesion. To meet this objective, the lexical ties are analyzed in relation to the conjunctive relations used.

\subsection{Subjects}

The participants in this study are first-year and third-year university students. They are from the same linguistic background. Students in Morocco study Arabic and French at primary school, middle school, and high school, and start learning English at grade nine when they take a two-hour class every week in which they are introduced to some basics of grammar, vocabulary, and functions. At grade ten, the number of hours devoted to learning English increases to four hours for literature students and three hours for science students. During the three years of language teaching in high school the focus is on teaching grammar, reading comprehension, and writing, especially in the twelfth grade when students are expected to take a final exam in English. The exam is written; hence the teachers' focus is on instruction in writing. Even the quizzes and tests administered to assess the students' learning are written. If students want to join the English department when they get their high school diploma, they have to take an entrance test which determines their proficiency in the language. They have to take an oral test first, but if they do not perform well on it, they have to take a written one.

\subsection{Data Collection and Sampling}

The data collection took place in May 2012 in Mohamed V University in Rabat and Choaib Dokkali University in El Jadida, both in Morocco. The instrument used for analysis in this study is the students' essays. Eighty students participated in the study. They were given one argumentative topic to write on: Some people prefer to marry when they are young, while others prefer to wait until they are older to marry. Make a case for which you think is better and why. The writing process took place in the classroom in one hour; students could not use dictionaries or other reference books. Before writing, students were given fifteen minutes to discuss their ideas in groups to control for any variation that might arise as a result of familiarity with the topic. The essays were scored holistically by two teachers and the researcher, and given grades of 1 to 3 out of 10 for the weak ones, 4 to 5 out of 10 for the averages ones, and 6 to 7.5 out of 10 for the strong ones. Twenty essays were selected randomly, ten from those that were rated high and ten from those that were rated low, thereby creating two proficiency levels.

\subsection{Method of Analysis}

The analysis is based ona heuristic approach using the taxonomies of Halliday and Hasan (1976) and Hoey (1991). The lexical ties, along with the conjunctive ties, in the essays produced by students from the two different proficiency groups are countedand analyzed quantitatively using the independent sample T-test. The objective is to compare the two groups in terms of the lexical ties and conjunctions they use. The variable of essay length is controlled through counting the number of words in each essay. The excerpts analyzed do not exceed 150 words.

\section{Results}

Table 1. Differences between the two proficiency groups in terms of their use of the reiteration relations

\begin{tabular}{lcccc}
\hline & $\mathrm{F}$ & $\mathrm{T}$ & Sig. (2-tailed) & Mean Difference \\
\hline Simple Lexical Repetition & 2.377 & 3.458 & .003 & 4.10000 \\
Complex Lexical Repetition & .111 & 2.114 & .049 & -1.50000 \\
Synonymy & 1.847 & 1.306 & .208 & -60000 \\
Near Synonymy & 4.556 & 1.518 & .158 & .80000 \\
Superordinate & .005 & .115 & .910 & .10000 \\
Antonymy & .159 & 1.210 & .242 & -70000 \\
Conjunctions & .178 & .087 & .932 & .10000 \\
\hline
\end{tabular}

The independent sample T-test demonstrates significant differences between the two proficiency levels in terms of the simple lexical repetition and complex lexical repetition used, the $\mathrm{P}=0.003$. The less proficient students in Group $1(\mathrm{M}=10.20, \mathrm{SD}=3.08)$ use more simple lexical repetition than the more proficient students in Group 2 do $(\mathrm{M}=6.1, \mathrm{SD}=2.13), \mathrm{t}(18)=3.45, \mathrm{P}=.003$, while students in Group $2(\mathrm{M}=2.40, \mathrm{SD}=1.64)$ use more complex lexical repetition than students in Group $1(\mathrm{M}=3.90, \mathrm{SD}=1.52) \mathrm{T}(17.89)=0.49, \mathrm{P}=0.49$. The two groups did not 
differ in their use of synonymy and near synonymy, $\mathrm{P}>.05$.

Table 2. The means of the reiteration relations and conjunctions in the two groups

\begin{tabular}{lccccc}
\hline Lexical Ties & Group & $\mathrm{N}$ & Mean & Std. Deviation & \\
\hline Simple Lexical Repetition & 1.00 & 10 & 10.2000 & 3.08401 & .97525 \\
& 2.00 & 10 & 6.1000 & 2.13177 & .67412 \\
Complex Lexical Repetition & 1.00 & 10 & 2.4000 & 1.64655 & .52068 \\
& 2.00 & 10 & 3.9000 & 1.52388 & .48189 \\
Synonymy & 1.00 & 10 & .3000 & .67495 & .21344 \\
& 2.00 & 10 & .9000 & 1.28668 & .40689 \\
Near Synonymy & 1.00 & 10 & 1.1000 & 1.59513 & .50442 \\
Superordinate & 2.00 & 10 & .3000 & .48305 & .15275 \\
& 1.00 & 10 & 1.7000 & 1.76698 & .55877 \\
Antonymy & 2.00 & 10 & 1.6000 & 2.11870 & .66999 \\
Conjunctions & 1.00 & 10 & 2.3000 & 1.25167 & .39581 \\
& 2.00 & 10 & 3.0000 & 1.33333 & .42164 \\
& 1.00 & 10 & 6.2000 & 2.52982 & .80000 \\
& 2.00 & 10 & 6.1000 & 2.60128 & .82260 \\
\hline
\end{tabular}

A close look at the means in table 2 indicates that both groups rarely rely on synonyms or near synonyms in their writings. The use of the superordinate is quite similar in both groups. The means in both groups respectively are $\mathrm{M}=1.70, \mathrm{M}=1.60$. The use of antonyms is apparently similar in both groups, $\mathrm{P}>.05$ with respective means of $\mathrm{M}=2.30, \mathrm{M}=3.00$. This implies that students in both grade levels rely less on antonyms as cohesive links. The use of conjunctions in both groups is not a distinguishing variable, $p>.05$. Both groups use approximately the same number of conjunctions in their essays.

Table 3. Comparison of the Means to determine the lexical ties that are most frequently used

\begin{tabular}{|c|c|c|c|c|c|c|c|c|}
\hline \multicolumn{2}{|c|}{ Group } & $\begin{array}{c}\text { Simple } \\
\text { Lexical } \\
\text { Repetition }\end{array}$ & $\begin{array}{c}\text { Complex } \\
\text { Lexical } \\
\text { Repetition }\end{array}$ & Synonymy & $\begin{array}{c}\text { Near } \\
\text { Synonymy }\end{array}$ & Superordinate & Antonymy & Conjunctions \\
\hline \multirow{4}{*}{1.00} & Mean & 10.2000 & 2.4000 & .3000 & 1.1000 & 1.7000 & 2.3000 & 6.2000 \\
\hline & $\mathrm{N}$ & 10 & 10 & 10 & 10 & 10 & 10 & 10 \\
\hline & Std. Deviation & 3.08401 & 1.64655 & .67495 & 1.59513 & 1.76698 & 1.25167 & 2.52982 \\
\hline & Mean & 6.1000 & 3.9000 & .9000 & .3000 & 1.6000 & 3.0000 & 6.1000 \\
\hline \multirow[t]{2}{*}{2.00} & $\mathrm{~N}$ & 10 & 10 & 10 & 10 & 10 & 10 & 10 \\
\hline & Std. Deviation & 2.13177 & 1.52388 & 1.28668 & .48305 & 2.11870 & 1.33333 & 2.60128 \\
\hline \multirow{3}{*}{ Total } & Mean & 8.1500 & 3.1500 & .6000 & .7000 & 1.6500 & 2.6500 & 6.1500 \\
\hline & $\mathrm{N}$ & 20 & 20 & 20 & 20 & 20 & 20 & 20 \\
\hline & Std. Deviation & 3.32890 & 1.72520 & 1.04630 & 1.21828 & 1.89945 & 1.30888 & 2.49789 \\
\hline
\end{tabular}

For a more descriptive analysis of the Moroccan learners' use of reiteration relations, a comparison of the means was regarded as necessary to determine the type of lexical cohesive ties that are more frequently used by the learners. Table 3 demonstrates that both groups rely more on simple lexical repetition than on complex lexical repetition in their argumentative writings. The statistical analysis also includes the use of conjunctions to compare the learners' use of lexical cohesion to their use of conjunctions. 


\section{Discussion}

The results of the study are compatible with Connor's findings concerning cohesive density, which does not distinguish good writing from poor writing. Approximately the same number of lexical cohesive ties was used by students in both proficiency levels. However, the developmental aspect of cohesion, which was discussed by Connor and many other researchers, including Crowhurst (1987), Ferris (1994), Cherry and Cooper (1980), and Witte and Faigley (1981), is not apparent in the current study. This finding may be attributed to many possible factors. First of all, cohesion development is related to vocabulary development (Carrell, 1983). Moroccan learners, however, do not receive formal instruction in vocabulary. That is, vocabulary acquisition is left to the students' initiative. Secondly, in the textbooks used at all grade levels, cohesion is associated merely with conjunctions. In this regard, the activities used focus only on explicit ways of linking sentences. Sometimes students are asked not to overuse the linking words, but they are not taught other ways to link their ideas. This phenomenon is confirmed in the statistical analysis above, which demonstrates that Moroccan learners overuse conjunctions. Even in writing classes, teachers do not introduce students to different ways to link their ideas. This practice results in writings that are not natural and are full of repetition and explicit conjunctions. Another problem is related to the position of conjunctions in the sentences. Most of the time, they are located at the beginning of the sentence, which is typical of EFL students' writings.

The overuse of repetition is another issue in foreign language learners. Moroccan students use too much repetition. For many researchers, this tendency is attributed to the influence of their mother tongue, which is Arabic, because repetition is an aspect of Arabic rhetoric. To minimize the learners' use of repetition, teachers may encourage them to use synonyms or near synonyms.

\section{Implications of the Study}

The problem with lexical cohesion is a question of awareness as indicated by many researchers (Kafes, 2012; McGee, 2009). It should be brought to the learners' awareness that cohesion in their writings is achieved through the use of different types of cohesive devises and thatthe use of conjunctions is not the only way to connect sentences. Writing teachers should be aware that teaching vocabulary should be part of the writing syllabus because cohesion, as mentioned earlier, is mainly lexical. If students do not have an appropriate working vocabulary to say what they want to say, they will resort to the use of conjunctions and write unnatural and uncohesive texts.

\section{Conclusion}

This study looked into the use of lexical cohesion in foreign language writing. The results of the studyindicate thatforeign learners of English use repetition as a cohesive tie more than any other tie because they do not know other ways to connect their paragraphs to form a unified whole. Teachers also should be aware that lexical cohesion is a main contributor to text coherence. In this sense, it has to be taught explicitly to improve the learners' writing.

\section{References}

Carrell, P. (1982). Cohesion is not coherence. TESOL Quarterly, 16(4), 479-488. Retrieved April 27, 2013, from http://www.jstor.org/stable/3586466

Carrell, P., \& Eisterhold, J. (1983). Schema theory and ESL reading pedagogy. TESOL, 17(4), 553-573. Retrieved April 27, 2013, from http://www.jstor.org/stable/3586613

Carrell, P. (1984). The effects of rhetorical organization on ESL readers. TESOL, 18(3), 485-500. Retrieved April 27, 2013, from http://www.jstor.org/stable/3586714

Cherry, R., \& C. Cooper. (1980). Cohesive ties and discourse structure: A study of average and superior texts at four grade levels. Unpublished Manuscript. Department of Learning and Instruction. State University of NY at Buffallo.

Conner, U. (1984). A study of cohesion and coherence in English as a second language students' writing. Papers in Linguistics: International Journal of Human Communication, 17, 301-316. http://dx.doi.org/10.1080/08351818409389208

Crowhurst, M. (1987). Cohesion in argument and narration at three grade levels. Research in the teaching of English, 21, 185-201. Retrieved April 26, 2013, from http://www.jstor.org/stable/40171109

De Beagrand, R., \& Dressler, W. (1981). Introduction to text linguistics. London, Longman.

Ferris, D. R. (1994). Lexical and syntactic features of ESL writing by students at different levels of L2 
proficiency. TESOL Quarterly, 28(2), 414-420. Retrieved April 17, 2013, from http://www.jstor.org/discover/10.2307/3587446

Halliday, M., \& Hasan, R. (1976). Cohesion in English. London: Longman.

Hasewell, R. H. (1988). Critique: Length of text and the measurement. Research in the teaching of English, 22(4), 305-319. Retrieved from http://www.jstor.org/discover/10.2307/40171197

Hilali Ben Daoud, F. Z. (2000). Cohesion and coherence in EFL writing, the case of Moroccan university students. Ph.D. Dissertation. Faculty of letters Department of English.

Hoey, M. (1991). Patterns of lexis in text. Oxford University Press.

Markels, R. B. (1983, September). Cohesion paradigms in paragraphs. College English, 45(5), 450-464. Retrieved from http://www.jstor.org/discover/10.2307/376843

Morgan, J., \& Sellner, M. (1980). Discourse and Linguistic Theory. In Spiro, R., Bruce, B., \& Brewer, W. (Eds), Theoretical Issues in Reading Comprehension (pp. 165-197). Hillsdale NJ: Lawrence Erlbaum Associates.

Sinclair, J. McH. (1998). The lexical item. In E. Weigand (Ed.), Contrastive Lexical Semantics (pp. 1-24). Amsterdam/Philadelphia: John Benjamins.

Stotsky, S. (1983). Types of lexical cohesion in expository writing: Implications for developing the vocabulary of academic discourse. CCC, 34(4), 430-447. http://dx.doi.org/10.2307/357899

Tanskanen, S. K. (2006). Collaborating towards Coherence. John Benjamins Publishing Company.

Widdowson, H. (1978). Teaching language as communication. London, Oxford.

Witte, S. P., \& Faigley, L. (1981, May). Coherence, Cohesion, and Writing Quality. College Composition and Communication, 32(2), 189-204. Retrieved March 19, 2013, from http://www.jstor.org/stable/356693

\section{Copyrights}

Copyright for this article is retained by the author(s), with first publication rights granted to the journal.

This is an open-access article distributed under the terms and conditions of the Creative Commons Attribution license (http://creativecommons.org/licenses/by/3.0/). 